\title{
Study of Laparoscopic Hiatus Hernia Repair at AVBRH
}

\author{
Dr. Tanu Pradhan ${ }^{1}$, Dr. Meenakshi Yeola ${ }^{2}$, Dr. Akshay Bora ${ }^{3}$ \\ ${ }^{1}$ Resident, Department of Surgery, Jawaharlal Nehru Medical College, Sawangi, Wardha, India \\ ${ }^{2}$ Professor, Department of Surgery, Jawaharlal Nehru Medical College, Sawangi, Wardha, India
}

\begin{abstract}
Hiatus hernia is a condition involving herniation of the contents of the abdominal cavity, most commonly the stomach, through the diaphragm into the mediastinum. In the United States, hiatus hernia was listed as a primary or secondary cause of hospital admissions in 142 of 10000 inpatients between 2003 and 2006.because of high mortalty associated with this condition, elective repair is advised wherever paraesophageal hernia is found 25 cases having hiatus hernia with GORD were included in the study. All cases were operated in AVBR Hospital with Laparoscopic fundoplication.

-Nissen procedure was performed

-Manometry was not available, hence could be done in only 3 patients as they were willing to go to Asian institute.(hyderabad)

-24 hr ph monitoring couldn't be done as it's a rural set up.

-Hospital stay, mean hospital stay for patient was 5-6 days.

Immediate post operatively complications were seen in 3 patients in which 2 presented with pneumothorax which were managed by ICD insertion for 3 days and 1 presented with severe belching which was managed conservatively. Laparoscopic repair has allowed shorter hospitalization (3-4 days) and recovery with shortand long term results comparable to open repair with either an abdominal or thoracic approach. Elective laparoscopic surgical reduction and repair has an excellent success rate with low morbidity and mortality. Being a rural set up most of the patients we received were in advanced disease and few cases had herniation of entire stomach into thorax. Laparoscopic management of hiatus hernia is standard technique for management,even in advance cases.
\end{abstract}

Keywords: Hiatus hernia, Laparoscopic nissin repair, Advance stage hiatus hernia, Manometry

\section{Introduction}

A) Hiatus hernia is a condition involving herniation of the contents of the abdominal cavity, most commonly the stomach, through the diaphragm into the mediastinum (1).

b) The current anatomic classification has evolved to include a categorization of hiatal hernias into Types I-IV.

Type I: sliding hiatal hernia, there is a widening of the muscular hiatal tunnel and circumferential laxity of the phrenoesophageal membrane, allowing a portion of the gastric cardia to herniate upward.(2)

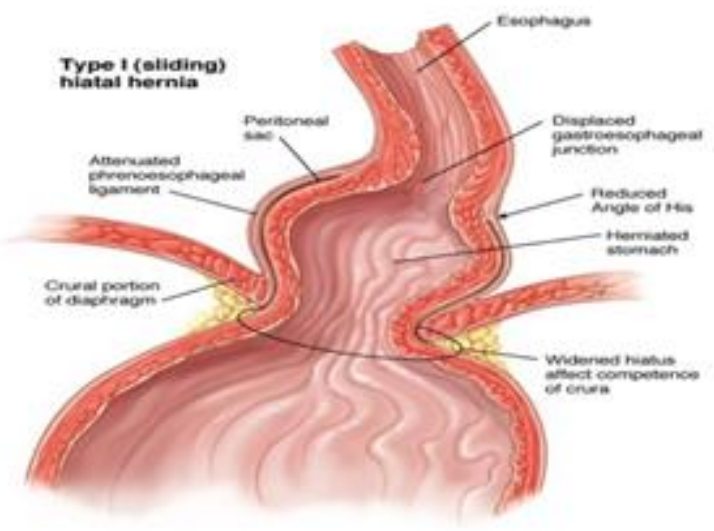

Type II: hernia results from alocalized defect in the phrenoesophageal membrane while the gastroesophageal junctionremains fixed to the preaortic fascia and the median arcuate ligament(3

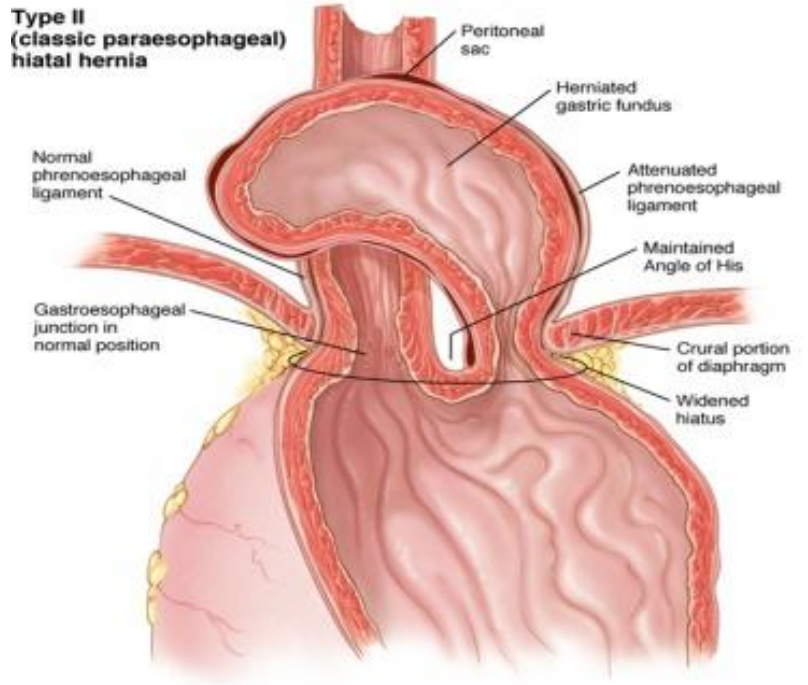

Type III Type III hernias have elements of both types I and II hernias. With progressive enlargement of the hernia through the hiatus, the phrenoesophageal membrane stretches, displacing the gastroesophageal junction above thediaphragm, thereby adding a sliding element to the type II hernia.(4) 


\section{International Journal of Science and Research (IJSR) \\ ISSN (Online): 2319-7064}

Index Copernicus Value (2013): 6.14 | Impact Factor (2015): 6.391

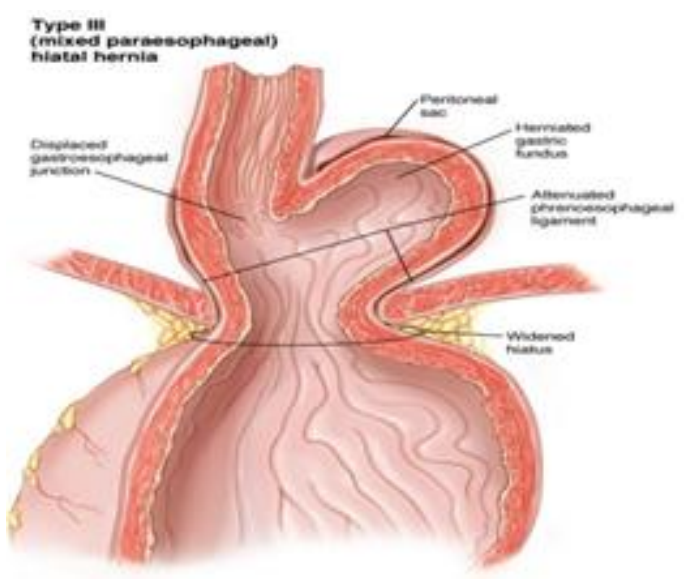

Type IV hiatus hernia isassociated with a large defect in the phrenoesophageal membrane, allowing other organs, such as colon, spleen, pancreas and small intestine to enter the hernia sac.

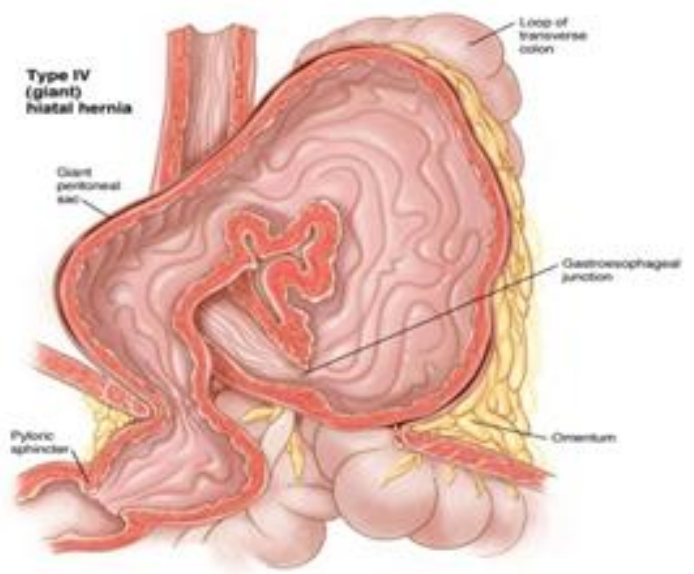

\section{Diagnosis}

Upper gastrointestinal endoscopy is essential in diagnosis and evaluation of potential complications from hiatus hernia that may explain symptoms (bleeding, dysphagia, pain). Sliding hiatus hernia is diagnosed when the apparent separation between the squamocolumnar junction (the transition fromesophageal to gastric epithelium) and the constriction formed asthe stomach traverses the hiatus is greater than $2 \mathrm{~cm}(3)$

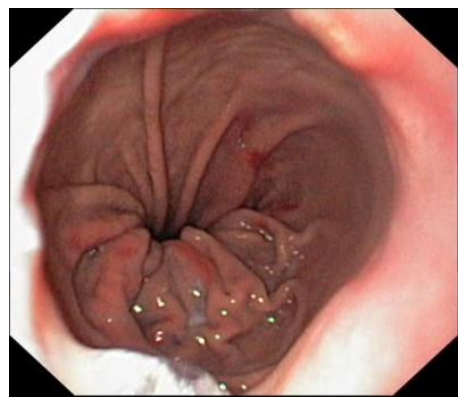

- Double contrast barium swallow is the preferred mode of examination

- A barium-meal examination in a patient with a sliding hiatal hernia that demonstrates the supradiaphragmatic location of the gastroesophageal junction.

\section{Computed tomography}

- CT scanning is particularly useful in the accurate anatomic depiction of a totally intrathoracic stomach, especially in patients in whom volvulus of the stomach is suspected.

- CT scanning is also useful for staging purposes in patients in whom a carcinoma complicates a hiatal hernia. Dehiscence of diaphragmatic crura of more than

- $15 \mathrm{~mm}$ may be seen.(4)

\section{Treatment}

- Proton pump inhibitors (PPIs) are the most potent inhibitors of gastric acid secretion and the most effective drugs to treat reflux esophagitis and typical symptoms of GERD.(5-7)

- Histamine 2 receptor antagonists and antacids are

- Alternatives to PPIs, though they are substantially

- Less effective.(5-7)

- Surgery is the only way to restore herniated organs into the abdominal cavity and to compensate for the functional abnormalities associated with hiatus hernia (8)

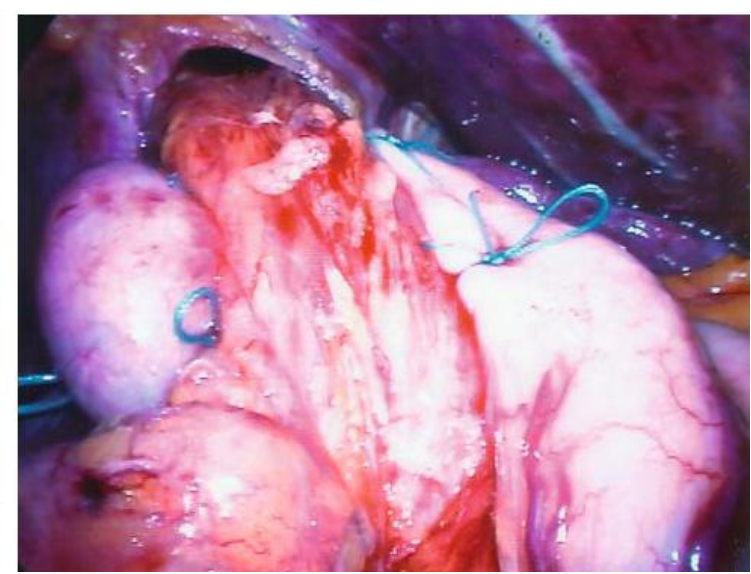

complete (Nissen $\left.360^{\circ}\right)$ fundoplication around the esophagus.
The standard procedure is currently laparoscopic fundoplication. The essential components of this technique are mobilizationof the distal esophagus, reduction of the associated hiatus hernia, and either partial (Toupet $270^{\circ}$ ) or

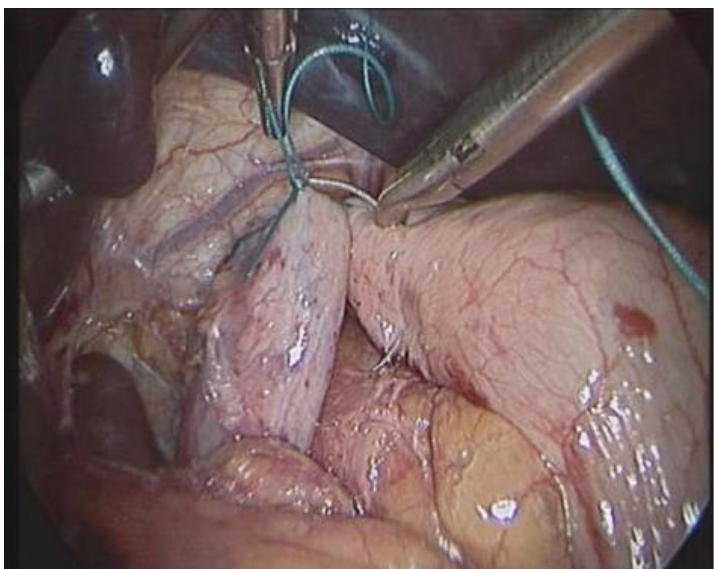

Volume 5 Issue 6, June 2016 www.ijsr.net

Licensed Under Creative Commons Attribution CC BY 


\section{International Journal of Science and Research (IJSR)}

ISSN (Online): 2319-7064

Index Copernicus Value (2013): 6.14 | Impact Factor (2015): 6.391

Aim

To study laparoscopic Hiatus Hernia repair at Acharya Vinoba Bhave Rural Hospital, Wardha

\section{Objectives}

- To study the demographic profile

- To study the symptomatology and mode of presentation

- To study the complication of hiatus hernia repair

\section{Materials and Method}

- In this prospective study,25 patients with Hiatus Hernia were enrolled, between May 2014 to August 2015, with a common complaint of dysphagia, weight loss, anemia, cough, heartburn, regurgiation and hoarseness of voice.

- After taking a detailed History along with Clinical Examination, patients were subjected to routine Hematologic \& Imaging investigations. Final diagnosis was made after Upper GI Endoscopy, HRCT/Barium study and Manometry.

- All the patients were operated laparoscopically under General Anaesthesia.

Following parameters were studied

Intraoperative blood loss

Operating time

Hospital stay

Complications

\section{Results and discussion}

- Patient came to us were between the age group of $40-70$ yrs

\begin{tabular}{|c|c|c|}
\hline Age group & Male & Female \\
\hline$<40$ & 2 & 2 \\
\hline $41-50$ & 2 & 4 \\
\hline $51-60$ & 1 & 4 \\
\hline $61-70$ & 4 & 6 \\
\hline
\end{tabular}

- During the study period, 25 cases with Hiatus Hernia were identified, 9 out of 25 were males and 16 were females.

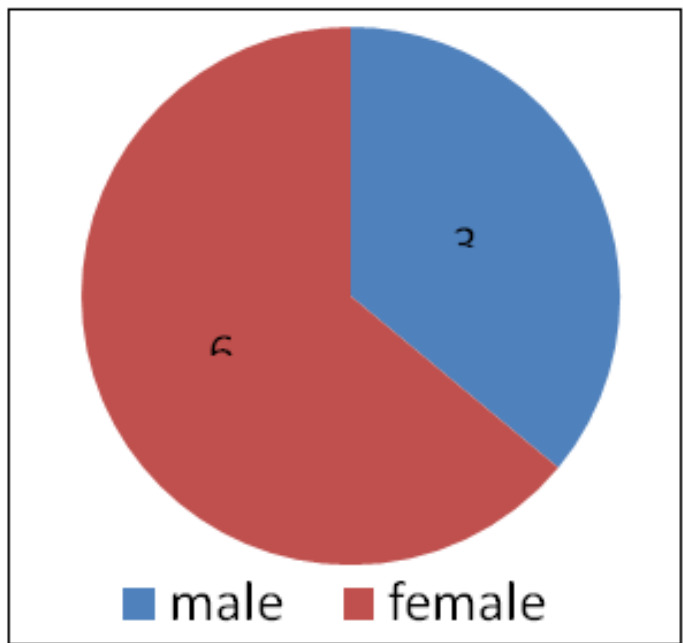

- Out of 25 patients, 22 patients presented with symptoms of GERD ( i.e. regurgiatation, heartburn, belching) and 3 patients presented with persistent vomitings and dysphagia.

- Out of 25 patients, 13 presented with grade-II, 11 patients presented with Grade-III and 1patient presented with Grade-IV hiatus hernia.

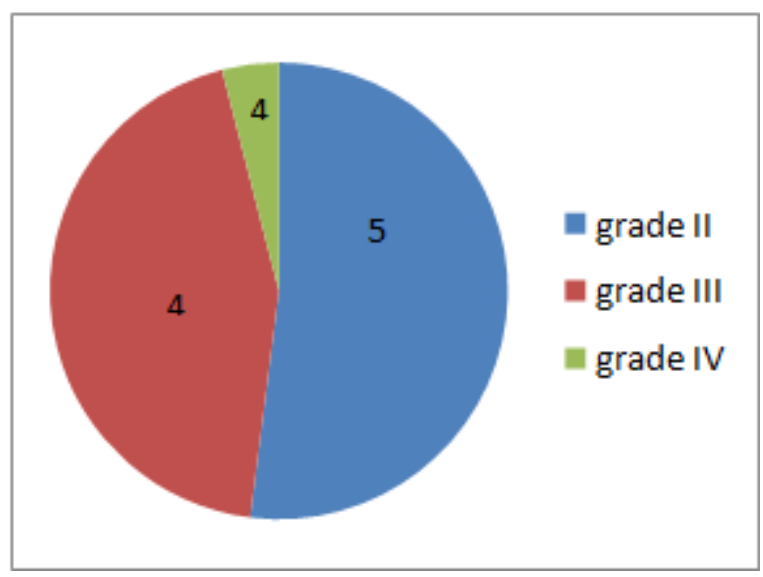

\section{Results and discussion}

- Intraoperative blood loss was 25-30 cc

- Operating time was $80 \mathrm{~min}$

- Hospital stay was 5-6 days

- Complications:

3 patients had complications in which 2 patients had pneumothorax which was managed by intercoastal drainage and 1 had belching which was managed conservatively.

\section{Conclusion}

- Laparoscopic fundoplication is the treatment of choice for severe gastroesophageal reflux disease.

- Proper patient selection and preoperative evaluation are essential for good results.

- With expert hands and advancement in technology,laparoscopic repair of hiatus hernia provides excellent exposure of surgical field and advantageous in terms of minimum blood loss,reduced morbitdity,rapid recovery inspite of elderly patients and multiple comorbidities.

- Laparoscopic fundoplication is the treatment of choice for severe gastroesophageal reflux disease.

- Proper patient selection and preoperative evaluation are essential for good results.

- With expert hands and advancement in technology,laparoscopic repair of hiatus hernia provides excellent exposure of surgical field and advantageous in terms of minimum blood loss,reduced morbitdity,rapid recovery inspite of elderly patients and multiple comorbidities.

\section{References}

[1] Thukkani N, Sonnenberg A. The influence of environmental risk factors in hospitalizationfor gastrooesophageal reflux disease-related diagnoses in the United States. AlimentPharmacol Ther 2010;31:852-61.

[2] Marchand P. The anatomy of esophageal hiatus of the diaphragm and the pathogenesis of hiatus herniation. Thorac Surg 1959;37:81-92.

Volume 5 Issue 6, June 2016 www.ijsr.net 


\section{International Journal of Science and Research (IJSR) \\ ISSN (Online): 2319-7064}

Index Copernicus Value (2013): 6.14 | Impact Factor (2015): 6.391

[3] Skinner, DB. Hernias (hiatal, traumatic, and congenital). In: Berk, JE., editor. Gastroenterology. 4. W.B. Saunders; Philadelphia: 1985. p. 705-716.Chapter 53

[4] Kahrilas et al. Page 2 Best Pract Res Clin Gastroenterol. Author manuscript; available in PMC 2009 January 1.NIH-PA Author Manuscript NIH-PA Author Manuscript NIH-PA Author Manuscript

[5] Shaheen NJ, Weinberg DS, Denberg TD, Chou R, Qaseem A, Shekelle P. Upper endoscopy for gastroesophageal reflux disease: best practice advice from the clinical guidelines committee of the American College of Physicians. Ann Intern Med 2012;157:80816.

[6] BMJ 2014;349:g6154 doi: 10.1136/bmj.g6154 (Published 23 October 2014)

[7] Kahrilas PJ, Shaheen NJ, Vaezi MF, Hiltz SW, Black E, Modlin IM, et al. American Gastroenterological Association medical position statement on the management of gastroesophageal reflux disease.Gastroenterology 2008;135:1383-91,91 e1-5

[8] Katz PO, Gerson LB, Vela MF. Guidelines for the diagnosis and management of gastroesophageal reflux disease. Am J Gastroenterol 2013;108:308-28; quiz 29.

[9] Fuchs KH, Babic B, Breithaupt W, Dallemagne B, Fingerhut A, Furnee E, et al. EAESrecommendations for the management of gastroesophageal reflux disease. Surg Endosc2014;28:1753-73

[10] Rydberg L, Ruth M, Lundell L. Mechanism of action of antireflux procedures. Br J Surg 1999;86:405-10.

[11]BMJ 2014;349:g6154 doi: 10.1136/bmj.g6154 (Published 23 October 2014)

[12] The History of Surgery for Hiatal Hernia andGastroesophageal Reflux http://www.researchgate.net/publication/227248378

[13] Laparoscopic Surgical Treatment of Paraesophageal Hiatus Hernia EDWARD T. CHORY, M.D., F.A.C.S. Lancaster Surgery Group, P.C.

[14]SAGES Society of American Gastrointestinal and Endoscopic Surgeons http://www.sages.org

Volume 5 Issue 6, June 2016 www.ijsr.net 